\title{
Exploring Consumer Spending When Redeeming Online Daily Coupons: An Abstract
}

\author{
Chinintorn Nakhata, Anne Roggeveen, Ali Besharat, and James Stock
}

\begin{abstract}
Online daily coupons (ODCs) (e.g., Groupon) offer a large discount with a long redemption period when consumers prepay for given products or services. While these popular coupons present exciting new opportunities, retailers must understand how different factors under their control may impact consumers' spending at redemption. Building on anchoring and adjustment effect and semantic cue concreteness, the present research investigates the impacts of the coupon structure (e.g., acquisition cost and face value), the specificity of the coupon deal, and the specificity of the product or service information on consumers' spending at redemption. The results from four experiments demonstrate that consumers tend to adjust their spending according to the coupon face value rather than the coupon acquisition cost. Furthermore, the specificity of the deal information on the voucher during the acquisition increases consumers' spending. Finally, the specificity of the product information during the redemption escalates total spending, especially when the hedonic consumption goals are primed.
\end{abstract}

Reference Available Upon Request

C. Nakhata $(\triangle)$

Clarion University of Pennsylvania, Clarion, PA, USA

e-mail: cnakhata@clarion.edu
A. Roggeveen
Babson College, Babson Park, MA, USA
e-mail: aroggeveen@babson.edu

\author{
A. Besharat \\ University of Denver, Denver, CO, USA \\ e-mail: ali.besharat@du.edu \\ J. Stock \\ University of South Florida, Tampa, FL, USA \\ e-mail: jstock@usf.edu
}

